\title{
EVIDENCE FOR A LESS HIGH ACCEPTOR SUBSTRATE SPECIFICITY OF GASTRIC HISTAMINE METHYLTRANSFERASE: METHYLATION OF IMIDAZOLE COMPOUNDS
}

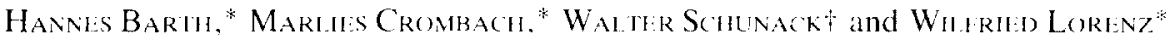 \\ ${ }^{*}$ Division of Experimental Surgery and Pathological Biochemistry, Department of Surgery, \\ University of Marburg, Robert-Koch-Str. 8. D-3550 Marburg/Lahn. F.R.G. \\ tInstitute of Pharmacy, University of Mainz. Saarstr. 21. D-65t) Mainz. F.R.G.
}

(Received 6 September 1979: accepted 17 December 1979)

\begin{abstract}
The transmethylation catalysed by HMT (EC 2.1.1.8)" has been considered as absolutely specific for histamine as acceptor substrate. In this investigation $N^{\prime \prime}-\mathrm{MH}, N^{\prime \prime}, N^{\prime \prime}$-DMH, spinaceamine and synthetically prepared 4-[(2-amino-ethylmercapto)-methyl]-imidazole could be identified as further methyl-group accepting substrates (optimum substrate concentration $\sim 1 \mathrm{mM}$ ), but the yield of extractable ${ }^{14} \mathrm{C}$-labelled methylation products was never greater than 21 per cent of that of histamine. The 3 per cent methylation of $N^{\prime r}, N^{\prime \prime}-$ DMH was considerably smaller than that of 33 per cent reported in the literature. This discrepancy was resolved and found to be ascribable to an inappropriate product extraction procedure used in the lormer experiments. When $N^{\prime \prime}$-MH and $N^{\prime \prime}$. $N^{\prime \prime}$-DMH were the substrates. the corresponding products were isolated by t.l.c. in four different solvent systems and identified to be $N^{\tau}, N^{\prime \prime}$-DMH and $N^{\tau}, N^{\prime \prime}, N^{\prime \prime}$-TMH. Thus HMT catalysed in all cases a uniform methylation of the $N^{u}$-nitrogen atom of the imidazole nucleus. The investigation of a series of various substituted imidazole compounds revealed that a methylation of the ring system had to be considered, if it wis not substituted in the $N^{\tau}$ - 2 - or $N^{\pi}$-position and if it carried a 4 -substituent with a strong basic aninogroup, whereas substitution in the ring 5 -position seemed to be of minor importance. Furthermore $\mathrm{H}_{1}$-receptor antagonists, $H_{2}$-receptor antagonists, the non-imidazole $H_{2}$-receptor agonist dimaprit, as well as the enzyme inhibitors aminoguanidine, tranylcypromine, pargyline and nicotinamide. were not methylated under the catalysis of HMT. The evidence for a less high substrate specificity of HMT may influence the relevance of histamine determinations using this cnzyme: caution seems necessary.
\end{abstract}

The transmethylation catalysed by histamine methyltransferase (HMT, $S$-adenosylmethionine: histamine $N$-methyltransferase, EC 2.1.1.8) has been considered as absolutely specific for histamine as acceptor substrate $[1-3]$. However, after the observation that $N^{*}$-methylhistamine $\left(N^{* x}-\mathrm{MH}\right)$ could also serve as methyl-group acceptor substrate [4], the assumption of an extremely high substrate specificity of HMT had to be given up.

At present there exist several reasons to reinvestigate this substrate specificity of HMT:

(1) Tests for radioenzymatic $[5,6]$ and fluorescence-enzymatic histamine determinations 171 depend on the high acceptor substrate specificity of HMT. A less high specificity could affect the reliability of these procedures.

(2) Contradictory results were reported about the existence of $N^{\prime \prime}$-MH and $N^{\prime \prime}, N^{\prime \prime}$-dimethylhistamine $\left(N^{*}, N^{*}-\mathrm{DMH}\right)$ in gastric tissue [8-12] and body fluids [13-14]. Evidence for their metabolism could significantly influence the discussion about their occurrence in certain tissues and their regulatory function. e.g. in gastric acid secretion $[15,16]$. Since stores for

* Abbreviations-HMT, histamine methyltranslerase: MH. methylhistamine: DMH. dimethylhistamine: TMH. trimethylhistamine. these substances are unknown, it may be that they could be grasped by identifying their metabolites.

(3) Knowledge about the enzymatic properties of HMT is still rather poor. Identification of the methylation products of $N^{*}$ - $\mathrm{MH}$ and of further acceptor substrates would be of considerable interest. Since histamine was only methylated at the $\tau$-nitrogen of its imidazole nucleus $[5,15]$ the methylation products at least for 4-substituted imidazole ring systems were expected to be the corresponding $N^{\top}$-methylated compounds (e.g. for $N^{\alpha}$-MH $N^{+} . N^{\prime x}$-DMH and for $N^{\prime \prime}, N^{\prime \prime}$-DMH $N^{\tau}, N^{\prime \alpha}, N^{\prime *}$-trimethylhistamine $\left(N^{\tau}\right.$, $\left.\left.N^{* x}, N^{\alpha}-\mathrm{TMH}\right)[4]\right)$.

(4) HMT from several sources is activated by numerous compounds, such as methylated histamines [4], $\mathrm{H}_{1}$ - and $\mathrm{H}_{2}$-receptor agonists, antagonists and related compounds [17-19]. S-adenosy]-1-homocysteine analogues [20], and plasma substitutes [21]. It should be ruled out that this has totally or in part to be ascribed to methylation and extraction of radioactive products of those HMT-activating substances.

(5) Contradictory results were reported about the degree of methylation of $N^{*}, N^{*}$-DMH [4, 22]. This discrepancy should be evaluated using different procedures for HMT determination.

All these questions were investigated in this communication using only HMT from pig gastric mucosa. 


\section{MATERIALS ANI) METHODS}

\section{Materials}

Enzvme preparation. HMT was purified from the gastric mucosa of pig fundus, which contains a high concentration of this enzyme [23]. To get enough material the preparation was repeated four times: From the stomachs of two adult male Landrace pigs (regional slaughter-house). 95-115 g fundus mucosa was prepared by dissection. After homogenization with 2 vol. of ice-cold $0.01 \mathrm{M}$ sodium phosphate buffer ( $\mathrm{pH} 7.4)$ using a Ultraturrax homogenizer. the homogenate was centrifuged for $30 \mathrm{~min}$ at $37,000 \mathrm{~g}$ (Sorvall RC.2-B) and for 45 min at $14.3 .1000 \mathrm{~g}$ (Beckmann Spinco L2-75B) at $2^{\circ}$. After diluting $205-$ $215 \mathrm{ml}$ of the supernatant with the same volume of 0.01 M sodium phosphate buffer ( $\mathrm{pH} 7.4)$, the sample was filtered through a paper filter (Ederol, qual. $15)$.

A $380-395 \mathrm{ml}$ quantity of this enzymc solution (1620-1960 mg protein) which contained the whole enzyme activity was applied to a column of DEAEcellulose $\left(4.5^{\circ} \times 30 \mathrm{~cm}\right.$, equilibrated with $0.01 \mathrm{M}$ sodium phosphats buffer, pll 7 . t).

After washing the column with $1250 \mathrm{ml}$ of $11.11 \mathrm{M}$ sodium phosphate buffer ( $\mathrm{pH} 7.4$ ), the ensyne was eluted by a discontinuous gradient. The sime buffer was used containing increasing concentrations of sodium chloride $[0.2 \mathrm{M}(50)(1 \mathrm{ml}): 0.5 \mathrm{M}(50)(0 \mathrm{ml})$ : $1.0 \mathrm{M}(1000 \mathrm{ml}))$ (Fig. 1). The elution rate was 96 mlhr. For monitoring the appearance of the proteins and further details of fraction collecting sec Barth et al. $|17|$.

On the alverage. in these four enzyme preparations the purification was 45 fold (range 37-51 fold). the yield 77 per cent ( 70 sil per cent) (all compared with the crude homogenate) and the specific activity was $12.1)(9.6-16.7)$ nmoles $($ min $\times$ mg protein) (protein determination according to Lowry at al. $[2+\mid)$.

Reagents for determination and parification of HMT. 2,5-diphenyloxazole (PPO), 2.2'-p-phenylene-bis-(5-phenyloxazole) (POPOP) and tolucine (ail of scintillation grade). iso-amyl alcohol p.a.. t- $^{-}$ butanol Uvasol: ethanol p.a.. Folin-Ciocalteu's phenol reagent. all inorganic salts, acids and bases p.a. (all Merck, Darmstadt): S-adenosyl-1-[1+Cmethyl|methionine (45-60 m( ii/mmole. New Eng-

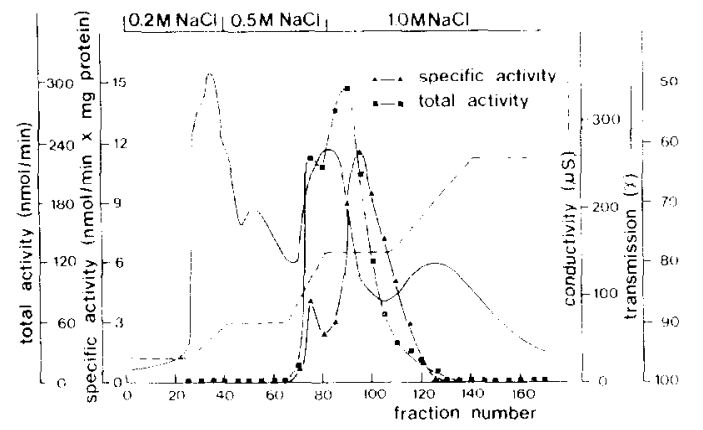

Fig. 1. Elution of HMT from a DEAE cellulose column using a discontinuous sodium chloride gradient. Elution wats performed using (0.0) $\mathrm{M}$ sodium phosphate huffer iptl 7.4) containing sodium chloride of the indicated comecntratiuns. For further details sec Materials and Nethols. land Nuclear. Boston, MA): S-adenosvil-1-methionine hydrogensulphate (Boehringer. Mannheim): $\left.\right|^{14}$ Clfoluene standard solution $19.2 \times 10$ d p.m. ml: Amersham Buchler. Braunschweig): DEAL-cellulose-SS p.a. (Serva. Heidelberg).

Reagents for t.l.r. Precoated glass plates (Silicat gel $60,20 \times 20 \mathrm{~cm}$, laver thickness $0.25 \mathrm{~mm}$, without fuorescent indicator), chloroform Uvasol. methanol

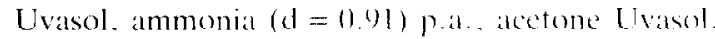
n-heptane Uvasol, fatst ble salt B LAB (0.5', solution $(w / v)$ in water), ninhvedrin sprate reagent (0. 1\% aerosol), iodine Suprapur (all Merck, Darmstadt). $N^{r} . N^{\prime \prime}$-DMH and $N^{\circ}, N^{\prime \prime} . N^{\prime \prime}-$ TMH were sunthesized by one of us (W.Sch) [25]. All aqueous solutions were prepared with twice distilled water.

Drugs. All drugs investigated were pure substances according to the statements of the companies. The generous supply of all these substances is greatly appreciated.

Histamine receptor agontists. Histamine dihsdrochloride puriss. (Fluka, Buchs): dimaprit is-13(N.N-dimethyl-amino)propyllisothiourtil!: $\quad V^{\prime \prime}$ guanyl-histamine|2-(4-imidalzolyl)-ethyl guanidinc|: 3. (t-imidazolyl)-propyl guanidine; $\mathrm{N}$ - 1 methyl-4-(2-aminothyl)-imidazole): 2-Mll 13methyl-4-(2-aminoethyl)-imidazole $\left|: V^{\pi}-\mathrm{MH}\right| 1-$ methyl-5-(2-aminoethyl)-imidazole : 5-Mll

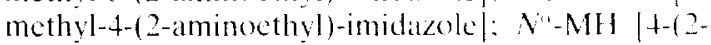
methylaminoethyl)-imidazole]: $N^{\prime \prime} \cdot N^{\prime \prime}-\mathrm{DM}$ II [t-1 2dimethylanino-cthyl)-imidazole) (all SKAF. Wel wyn Garden (ity): 5-ethylhistamine |5-ethyl-t-12aminoethyl)-imidazole ]: $N^{\circ}, 5-D M H$ [5-methyl-4-12methylamino-ethyl)-imidazole | fall wnthesized by one of us (W. Sch. )).

Histamine Hereceptor antegenists. The corresponding trade names and companies for the listed Hereceptor antagonists can be ohtaned from ref. 117|: antazoline. bamipine hrompheniramine. chlophemexamine, chlorpyramine, cinnopentarons. cyproheptadine dimethpyrindene. doxylamine. histapyrrodine, homophenazine, mebhydroline. nepyranine, piprinhydrinate, promethazine, tripelennamine, tolpropamine. WV 701

Histamine Ho-recepter antagonists. Burimamide. 5-stethyburimamide. thiaburimamide. metiamide. cimetidine (all SK\&F, Welwin (iarden (ity): ranitidine (Glaxo. Watre).

Imidazde componmes withent murked ations on histamine recepters. t-methylimidazole. thydroxymethylimidazole. 5-methyl-t-hydrosumethylimidi20le: (all SK\&l. Welwyn (iaden (ity) spinaceam-

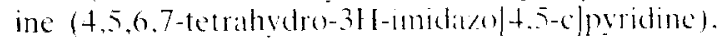
$4-\mid(2$ - anino - cthylmercapto $)-m e t h y) \mid-$ imidazole (Table 2, I), H-liz-amimo-ethylmercapto)-methylmethyl|-5-methylimidazolo (Tible 2 III) t-li2amino - ethvlmercapto) - methyll - 2 - methylimidazole (Table 2. IV) (all sonthesiad by one of us

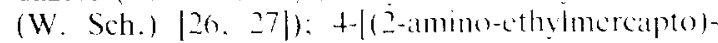
methyl]-5-methyl-imidazole (Table 2 II) (SK\&F. Welwy ciarden (ity) 11 -methyl-t-

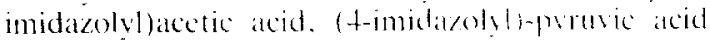

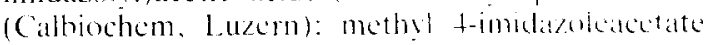

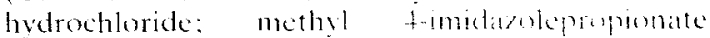
hydrochloride: 1-(t-imidazolsh-3-butamente |all wnthesized hy ane of us (W. Sid. I).

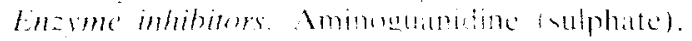


nicotinamide (both Merck, Darmstadt); pargyline (Abbott, Brussels): tranylcypromine (SK\&F, Welwyn Garden City).

\section{Methods}

Determination of HMT-activity according to Barth et al. [17]. HMT was determined by measuring the formation of $\mathrm{N}^{\tau}-\left[{ }^{14} \mathrm{C}\right]-\mathrm{MH}$ according to a modification of the method of Snyder and Axelrod [28]. The assays were carried out with $0.1 \mathrm{ml}$ of the partly purified HMT which contained an enzyme activity of about $400 \mathrm{pmolss} / \mathrm{min}$. Furthermore, in a final volume of the incubation mixture of $0.5 \mathrm{ml}$ the following substances were dissolved: S-adenosyl-1.methionine hydrogen sulphate 350 nmoles: S-adenosyl-L- $\left[{ }^{1+} \mathrm{C}\right.$-methyl]methionine 3.6 nmoles; histamine (optimum 58 nmoles) or other substances tested as methyl group acceptor substrates in varying amounts and sodium phosphate buffer (pH 7.4) $22.5 \mu$ moles.

The performance of the incubations, the preparation of blank values and the extraction of the products into a mixture of toluene and iso-amyl alcohol were the same as described by Barth ot al. $[17]$.

Counting of radioactivity in an aliquot of the organic extract was performed in a liquid scintillation spectrometer (Packard TriCarb 3380), 565 c.p.m. corresponded to the formation of 1 nmole $N^{\top}-\mathrm{MH}$ (recovery about 60 per cent).

The range of blank values was $695-805$ c.p.m. above the instrumental background of $30 \mathrm{c.p} . \mathrm{m}$. The efficiency of the counting procedure was tested by the addition of $50 \mu 1$ [ ${ }^{1 .} \mathrm{C} 7$ toluene standard solution (cf. Materials) to the organic phase obtained after incubation, extraction and centrifugation and was found to be 90 per cent on the average.

The extraction yield for the methylated products from the incubation mixture into the iso-amyl alcohol/toluene mixture was only known for $N^{-}$-MH [15]. Therefore absolute values could only be given for the methylation of histamine [expressed as pmoles $N^{2}-\mathrm{MH}$ formation $/(\min \times \mathrm{mg}$ protein $)$. whereas the methylation rates for all other compounds were expressed as per cent methylation compared to optimum $N^{r}$-MH formation gained at a final optimum histamine concentration of $1.16 \times$ $\left.10^{+} \mathrm{M}\right)$. Product formation below 1.5 per cent was indistinguishable from zero.

Determination of HMT-activity according to Gustafsson and Forshell [22]. In a few additional experiments the formed radioactive products were extracted into $n$-butanol (cf. [22]) instead into the mixture of iso-amyl alcohol/toluene. In these experiments the reactions were stopped after $0,15,30,45$ and $60 \mathrm{~min}$ by the addition of $0.2 \mathrm{ml} \mathrm{N} \mathrm{NaOH}$ (saturated with $\mathrm{Na}_{2} \mathrm{SO}_{4}$ ) and in the same vials the formed products were extracted into $2.0 \mathrm{ml}$ water-saturated $n$-butanol. A $0.5 \mathrm{ml}$ aliquot of the $n$-butanol phase was added to the scintillation mixture consisting of $10 \mathrm{ml}$ of toluene scintillator and $2 \mathrm{~m}$ ethanol. Since the yield of this $n$-butanol extraction procedure was not determined, values for these experiments were given in c.p.m./incubation time.

T.l.c.-identification of enzymatically formed $\mathrm{N}^{\mathrm{r}}, \mathrm{N}^{a}-D M H$ and $N^{\mathrm{r}}, N^{a}, N^{\mathrm{a}}-T M H$. Using $N^{\mathrm{a}}-\mathrm{MH}$ or $N^{\alpha}, N^{a}$-DMII as methyl-group accepting substrates of HMT radioactive methylation products could be extracted into this iso-amyl alcohol/toluene mixture. In order to get these substances in larger quantities for identification. 40 incubations of the above mentioned composition were run for $4 \mathrm{hr}, 20$ containing $N^{n}$-MH and the other $20 N^{n} . N^{n}$-DMH as substrate (final concentration of the substrates $10^{-+} \mathrm{M}$ ). Simultaneously with these 40 incubations another 60 were run, 20 without any methyl-group accepting substrate whose volume was replaced by $0.1 \mathrm{ml}$ $0.01 \mathrm{M}$ sodium phosphate buffer (p/l 7.4) and another $40\left(20\right.$ with $N^{2}-\mathrm{MH}$ and another 20 with $N^{a}, N^{a}$-DMH) using an enzyme solution which had been boiled for $10 \mathrm{~min}$. To simulate the conditions for routinely performed enzyme assays, the solvent extraction step was carried out separately for every incubation mixture. Then $5 \mathrm{ml}$ of the iso-amyl alcohol/toluene mixture were aspirated from each sample and collected for every group of 20 incubations. Each of the five combined extracts was concentrated in an evaporator to a final volume of $5(x)(0)$. After addition of $3.0 \mathrm{ml} n$-heptane and $0.5 \mathrm{ml}$ $0.1 \mathrm{~N} \mathrm{HCl}$, the mixture was shaken for 5 min and the supernatant fraction discarded by aspiration. For t.l.c.-identification $25 \mu$ samples of this acidic solution were mixed with 75 ul of acetone.

Twenty microlitres of standard solution (histamine and $N^{\tau}-\mathrm{MH} 0.1 \mathrm{mg} / \mathrm{ml}: N^{\prime \prime}-\mathrm{MH}$ and $N^{\tau} . N^{x}$-DMH $0.5 \mathrm{mg} / \mathrm{ml} ; \quad N^{*}, N^{*}{ }^{*} \mathrm{DMH}$ and $N^{\top}, N^{*}, N^{\prime \prime}-\mathrm{TMH}$ $2.5 \mathrm{mg} / \mathrm{ml}$ ) and $100 \mathrm{l}$ of the above described combined extracts were applied to silica gel coated glatss plates $1.5 \mathrm{~cm}$ from the bottom (Fig. 2). The spots were dried in a stream of warm air. In a glass developing tank lined with chromatographic paper (Whatman No. 1) dipping into the solvent each chromatogram was developed vertically to a line $10-12 \mathrm{~cm}$ above origin. The developing time of $50-65 \mathrm{~min}$ depended on the various solvent systems (I: chloroform/methanol/ammonia $(d-0.91)(60+35+5)$ : II: chloroform/methanol $(80+20)$, ammonia atmosphere: III: methanol (100), ammonia atmosphere: IV: $8 \%$ aqueous sodium chloride $(100)$,

After air-drying, the chromatograms were developed. Histamine and $N^{T}$-MH were indicated by purple spots which arose after spraying the plates with $0.1 \%$ ninhydrin aerosol and drying them at $65^{\circ}$ for 10 min; spraying the plates with fast blue salt $B$ $10.5 \%$ solution in water $(w / v)]$ and developing them in an ammonia atmosphere for $10-15 \mathrm{sec}$ visualized ochre spots corresponding to $N^{*}-\mathrm{MH}$ and $N^{r}, N^{*}$ -

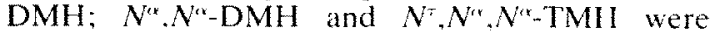
visualized by staining the plates with sublimated iodine in a glass tank (Fig. 2, panel a). In all cases the detection limit could be lowered by examining the plates using diaphanous light.

Radioactive spots were localized under a $2 \pi$ detector (LB 6280) of a t.l.c.-scanning device (LB 2723 equipped with power supply (BF 1017-1), amplifier/high-voltage unit (BF 2301), rate meter integrator (BF 2305), Autochron $x y$-recorder (LB 2740) and plotter (LB 2745); (all Berthold. Wildbad). Chromatograms were plotted (sham window $2.5 \times 2.5 \mathrm{~mm}$, scaling factor 4) and integrated (sham window $16 \times 1 \mathrm{~mm}, 1$ integration-cycle $\triangleq 100$ ) impulses/min) using a scanning speed of $300 \mathrm{~mm} / \mathrm{hr}$ (Fig. 2b). 


\section{$\mathbf{F} \rightarrow$ \\ a)}

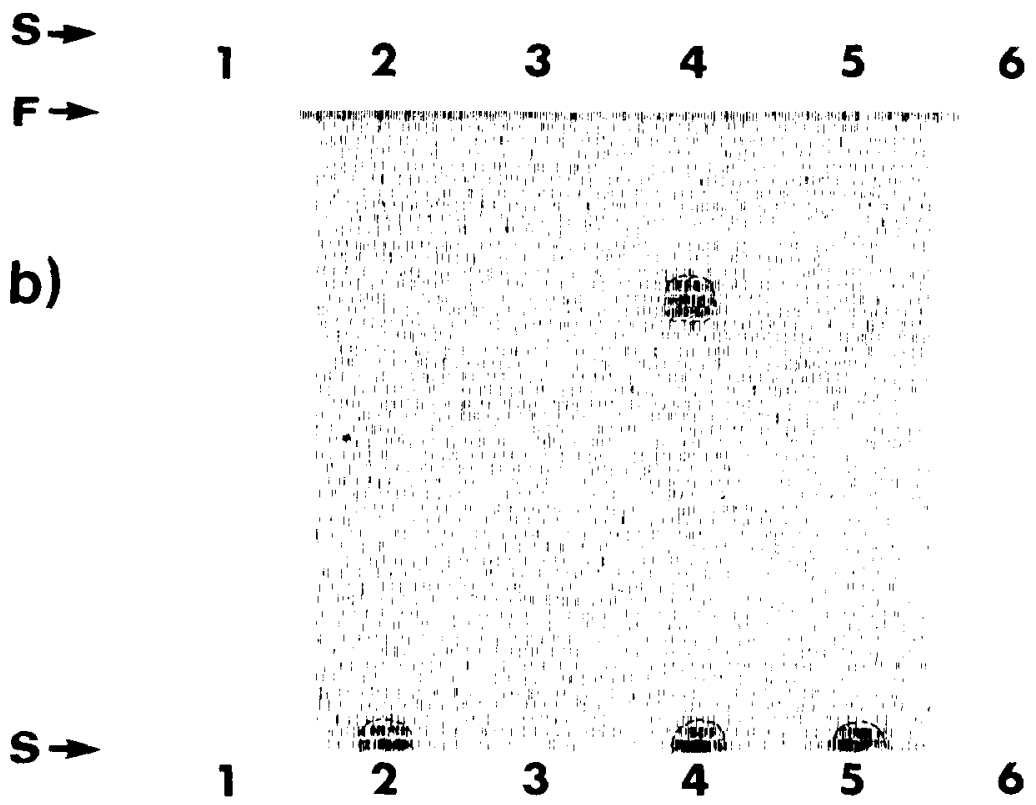

Fig. 2. Exemplary demonstration of a thin layer chromatogram (panel a) and its radioactivity plotler diagram (panel $b$ ) for the identification of methyl-group acceptor substrates of gastric HMT. Solvent system II; developing time 55 min; staining with sublimated iodine. $S=$ starting point; $F=$ front of the solvent mixture; 1: $40 \mu \mathrm{l} \leq 20 \mu \mathrm{g}$ authentic $N^{\mathrm{a}} . N^{u}$-DMH: $2: 20(1)$ of the extract from incubations withoul addition of any methyl-group acceptor substrate; $3: 40 \mu \mathrm{l} \bumpeq 20 \mu \mathrm{g}$ authentic $N^{\mathrm{N}}$. $N^{\prime \prime}$-DMH $+40 \mu \mathrm{A} 100 \mathrm{\mu g}$

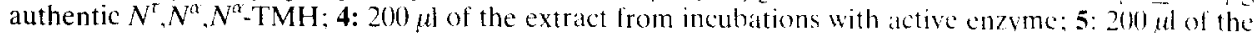

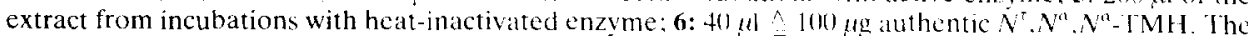
upper radioactive spot in panel b corresponds to the upper colour spot in panel a: both indicate enzymatically formed $N^{r}, N^{a}, N^{\mathrm{a}}$-TMH: the three radioactive spots $\left(R_{1}-0.05\right)$ in tracks 2.4 and 5 originate from an unknown impurity of $S$-itdenosyl $1 . \int^{1+} \mathrm{C}$ methyl|methionine. For better visualization in the photograph the amounts of substances indicated in Methods were doubled. For further details see Materials and Methods.

$R_{t}$-values were determined for each radioactive and colour spot.

\section{RESULTS}

Histamine analogues as methyl-group accepting substrates of gastric HMT. Various imidazole compounds (histamine reccptor agonists, $\mathrm{I}_{2}$-receptor antagonists and others without action at histamine receptors) as well as a number of substances used in research on biogenic amine metabolism (enzyme inhibitors) and pharmacology $\left(\mathrm{H}_{1}\right.$-receptor antagonis(s) were tested to serve as methyl-group acceptor substrates of HMT from pig fundus mucosa.

From this number of compounds two groups of imidazole compounds were found to be acceptor substrates: (1) Ring- and side-chain-methylated histamines (Table 1) as well as (2) I and its methylated analogues (Table 2). Under the chosen incubation conditions which were optimal for the determination of histamine methylation, none of those imidazole compounds was a better acceptor substrate than 
Table 1. Histamine and alkylated histamines as acceptor substrates of HMT from pig fundus mucosa*

\begin{tabular}{|c|c|c|c|c|c|}
\hline \multirow[b]{2}{*}{ Acceptor substrates } & \multirow[b]{2}{*}{$10^{-6}$} & \multicolumn{3}{|c|}{$\begin{array}{l}\text { Methylation }(\%) \text { at a } \\
\text { substrate concentration }(M) \text { of }\end{array}$} & \multirow[b]{2}{*}{$10^{-}$} \\
\hline & & $10^{-5}$ & $10^{-1}$ & $10^{-3}$ & \\
\hline Histamine & 24 & 64 & 96 & 53 & 32 \\
\hline$N^{\alpha}$-methylhistamine & 0 & 5 & 12 & 18 & 16 \\
\hline$N^{\alpha} \cdot N^{\alpha x}$-dimethylhistamine & 0 & 0 & 3 & 5 & 4 \\
\hline 5-methylhistamine & 0 & 0 & 0 & 2 & 3 \\
\hline 5-ethylhistamine & 0 & 0 & 0 & 2 & 2 \\
\hline 5. $N^{\alpha}$-dimethylhistamine & 0 & 0 & () & (1) & 2 \\
\hline$N^{\top}$-methylhistamine & () & 0 & 0 & () & () \\
\hline 2-methylhistamine & 0 & 0 & 3 & 5 & 5 \\
\hline$N^{*}$-methylhistamine & 0 & 0 & 0 & 0 & 0 \\
\hline Spinaceamine & 0 & 3 & 6 & 7 & 2 \\
\hline
\end{tabular}

* Incubations were carried out under conditions that were optimum for histamine ( $\mathrm{pH}$ $7.4 ;[5$-adcnosyl-L-methionine $]=0.71 \mathrm{mM}$; iso-amyl alcohol/toluene extraction procedure). Incubations containing histamine in a final concentration of $0.116 \mathrm{mM}$ equalled 100 per cent. Mean values from four to eight determinations. For further details of the incubation conditions and calculations of methylation rates see Materials and Methods.

histamine itself and the extracted radioactivity was never greater than 21 per cent. Beside the naturally occurring $N^{*}$ - $\mathrm{MH}$ only I could be methylated to a fairly good extent. Histamine, $N^{\alpha}-\mathrm{MH}, N^{\alpha}, N^{\alpha}-\mathrm{DMH}$ and spinaceamine as well as I showed substrate optima lying within an investigated concentration from $10 \mathrm{mM}$ to $1 \mu \mathrm{M}$. The one for histamine $(\sim 0.1 \mathrm{mM})$ was lower than those for $N^{\alpha}-\mathrm{MH}$ (2.5 mM; cf. [4]), $N^{\alpha}, N^{\alpha}$-DMH, spinacemine and I $(\sim 1 \mathrm{mM})$ by one order of magnitude. This relatively low optimum histamine concentration was also raised into the $\mathrm{mM}$-range $(0.4 \mathrm{mM})$, when the substrate inhibition of HMT by histamine was abolished by HMT-activating substances $[4,17,18], 2-\mathrm{MH}, 5$ MH, 5-ethylhistamine, 5, $N^{\circ}$-DMH as well as II and III (see Table 2) were methylated to a very small but measurable extent at concentrations above $1 \mathrm{mM}$. This increase in extractable radioactivity seemed to be unspecific, since no substrate optimum could be observed in the investigated range of substrate concentration.

All other imidazole compounds as well as the non-

Table 2. 4-[(2-Amino-ethylmercapto)-methyl|-imidazole and its methylated analogues as acceptor substrates of HMT from pig fundus mucosa*

No. Acceptor substrates
Methylation $(\%)$ at a substrate concentration $(M)$ of 10 $0^{\circ} 10^{-5} \quad 10^{-4} \quad 10^{-3} \quad 10^{-2}$
I<smiles>NCCSCc1c[nH]cn1</smiles>

II

III<smiles>Cc1[nH]cnc1CSCCN</smiles><smiles>Cc1[nH]cnc1C(C)SCCN</smiles>

IV<smiles>Cc1nc(CSCCN)c[nH]1</smiles>



${ }^{*} I=4-[(2$-amino-ethylmercapto $)$-methyl $]$-imidazole; II $=4-[(2$-amino-ethylmercapto $)$-methyl $\mid-5$-methyl-imidazole; III $=4-[(2$-amino-ethylmercapto $)$-methylmethyl $]-5$-methyl-imidazole; IV $=4-[(2$-aminoethylmercapto $)$-methy $]-2-$ methyl-imidazole.

For further details see legend of Table 1 . 
Tahle 3. Determination of radioactive methylation products from histamine and $N^{r y} N^{n t}-\mathrm{DMH}$ using two extraction procedures*

\begin{tabular}{|c|c|c|c|c|}
\hline \multirow{2}{*}{$\begin{array}{l}\text { Product extraction } \\
\text { procedure }\end{array}$} & \multirow{2}{*}{$\underset{(\min )}{\operatorname{Tim}}$} & \multicolumn{3}{|c|}{$\begin{array}{l}\text { Extracted radoactivity } \\
\text { (c.p.m. incubation time) }\end{array}$} \\
\hline & & Blanks: & $\mathrm{N}^{2} \cdot \mathrm{MH}^{+}$ & $N^{r} \cdot N^{t *} \cdot N^{n}-$ TMLI \\
\hline \multirow[t]{4}{*}{ iso-amyl alcohol/toluene } & 15 & 727 & +2020 & +19 \\
\hline & 30 & 741 & +4384 & +116 \\
\hline & 45 & 765 & +6702 & +193 \\
\hline & 60 & 796 & +8024 & +230 \\
\hline \multirow[t]{4}{*}{$n$-Butanol } & 15 & 4959 & +748 & $\cdots 20$ \\
\hline & 30 & 4839 & +1488 & -172 \\
\hline & 4.5 & $5(15)$ & +2299 & -74 \\
\hline & 60 & 4566 & +3334 & +77 \\
\hline
\end{tabular}

\footnotetext{
* Exemplary demonstration of onc out of four experiments. Every incubation was run (substrate concentration in all cases $0.1 \mathrm{mM}$ ) and stopped in double after various time intervals Then the formed products were extracted using the one or the other of the two extraction procedures described in Methods. Specific activity of HMT $0.63 \mathrm{nmoles} /(\mathrm{min} \times \mathrm{mg}$ protein): protein content $26 \mu \mathrm{g} /$ incubation mixture. For further details of the incubations see Materials and Methods.

$\uparrow$ Blanks subtracted.

Evidence for this reaction product is given later in the paper.
}

imidazole compounds dimaprit (histamine receptor agonist [29]), ranitidine $\left(\mathrm{H}_{2}\right.$-receptor antagonist [30]), $\mathrm{H}_{1}$-receptor antagonists and enzyme inhibitors (all listed in Materials) were not methylated under the catalysis of gastric HMT from pig fundus mucosa ( $N=4$ for every concentration investigated: range of concentration $1 \mu \mathrm{M}-10 \mathrm{mM}$ ).

Determination of the methylation rate of $\mathrm{N}^{a}, \mathrm{~N}^{\circ} D M H$ using two different product extraction procedures. Compared to histamine. $N^{n}, N^{n}$-DMH was a very poor methyl-group acceptor substrate for HMT $[2.3,2.5,2.6$ and 2.8 per cent methylation at $0.1 \mathrm{mM}$ final concentration (cf. Table 1); mean value from four determinations in four experiments]. whereas Gustafsson and Forshell [22] described this substance (also $0.1 \mathrm{mM}$ final concentration) to be methylated by 31 per cent compared to histamine. In order to elucidate this discrepancy, parallel incu bations for HMT-activity determinations were run using both the iso-amyl alcohol/toluene [17] and the butanol [22] extraction procedure, since this methodological difference seemed to contribute mainly to the observed contradictory results.

The blank values gained in the two procedures could explain a great part of the observed differences: Those obtained for the butanol extraction procedure were 6.4 times higher than those of the iso-amyl alcohol/toluene procedure (Table 3). Moreover in the butanol procedure blank values did not rise steadily with longer incubation time, but were distributed randomly, so that negative c.p.m.-readings could arise (Table 3 ). Thus, using histamine as methyl-group accepting substrate, the signal-blank ratio was 2.79-10.08 for the iso-amyl alcohol/toluene procedure, but only $0.15-0.73$ for the butanol extraction procedure, whereas ratio-values for the incubations with $N^{\prime \prime}, N^{\prime \prime}$-DMH were 0.03 to 0.29 and -0.03 to +0.02 . Table 3 shows one out of four identical experiments. Using the iso-amyl alcohol/toluene procedure, the methylation of $N^{\alpha}, N^{\alpha}$-DMH could be proven in all cases (see above). Using the butanol extraction procedure, however, only in one experiment a mean methylation rate of 1.6 per cent could be observed, whereas in 3 experiments radioactivity extracted from incubations with intact enzyme was slightly smaller than that extracted from blank incubations. These latter values are completely insufficient to detect any methylation of $N^{\alpha} . N^{\alpha}$-DMH at all.

Table $4 . R_{r}$-values of histamine and methylated histamines using four different solvent systems for development of t.l.c.-chromatogtams*

\begin{tabular}{|c|c|c|c|c|}
\hline \multirow[b]{2}{*}{ Compound } & \multicolumn{3}{|c|}{$\begin{array}{r}R_{\text {-values }} \begin{array}{r}\text { using } \\
\text { system }\end{array}\end{array}$} & solvent \\
\hline & 1 & II & [II & IV \\
\hline Histamine & 0.19 & 01,11 & 01.77 & 0.50 \\
\hline $\mathrm{N}^{\pi}-\mathrm{MH}$ & 0.34 & 01.42 & 0.80 & 0.36 \\
\hline$N^{x+}-\mathrm{MH}$ & 0.17 & 0.17 & 0.76 & 0.4 .5 \\
\hline $\begin{array}{l}N^{*} N^{\circ} \text {-DMH } \\
\text { (authentic) }\end{array}$ & 0.31 & 0.43 & 0.80 & 0.25 \\
\hline $\begin{array}{l}N^{2} N^{2} \text {-DMH } \\
\text { (enzymatically lormed) }\end{array}$ & 0.32 & 0.44 & 0.81 & 0.22 \\
\hline $\begin{array}{l}N^{n x}, N^{r k}-D M H \\
N^{r} \cdot N^{x}, N^{x x}-T M H\end{array}$ & 0.4 .3 & 0.52 & 0.77 & 0.39 \\
\hline (authentic) & 0.59 & 0.71 & $(1.81$ & 11.15 \\
\hline $\begin{array}{l}N^{\tau}, N^{*}, N^{\alpha} \text {-TMH } \\
\text { (enzymatically formed) }\end{array}$ & 0.58 & 0.71 & 0.80 & 0.16 \\
\hline S-Adenosyl-1-methionine & 0.58 & 0.33 & $<0.05$ & (1. 45 \\
\hline
\end{tabular}

* Plates: glass coated with silica gel 60 ; Solvent systems: $\mathrm{I}=$ chloroform/methanol/ammonia $(\mathrm{d}=0.91)(60+35$ $+5) ; \mathrm{II}=$ chloroform/methanol $(80+20)$, ammonia atmosphere; III = methanol $(100)$, ammonia atmosphere; IV $=8 \%$ aqueous sodium chloride $(100)$. For the preparation of standard solutions see Methods. Twenty microlitres of these corresponded to $2 \mu \mathrm{g}$ of histamine and $N^{*}$ $\mathrm{MH}$ as well as to $10 \mu \mathrm{g}$ of $N^{*}-\mathrm{MH}, N^{*}, N^{\alpha *}-\mathrm{DMH}, N^{\tau}, N^{*}$. DMH and $N^{\tau}, N^{r r} . N^{*}$-TMH. Staining: $0.5 \%$ fast blue salt B; $0.1 \%$ ninhydrin aerosol or iodine. Enzymatically formed methylation products were also localized under a t.l.c.scanning device. For further details see Materials and Methods. 
T.l.c.-identification of the methylation products of $\mathrm{N}^{\alpha}-M H$ and $\mathrm{N}^{\alpha}, \mathrm{N}^{\alpha}$-DMH formed under the catalysis of HMT. In four different solvent systems it could be shown that the reaction products isolated from the corresponding pool of 20 incubation mixtures (cf. Methods) containing $N^{* x}-\mathrm{MH}$ or $N^{r z} . N^{* t}$-DMH as substrate had the same $R_{t}$-values as authentic $N^{\tau}$, $N^{\alpha}$-DMH and $N^{\tau} \cdot N^{\alpha}, N^{\alpha}$-TMH (Table 4). In all systems, the $R_{f}$-values of the methylation products $\left(N^{-}-\right.$ MH $, N^{\tau}, N^{\alpha}$-DMH $, N^{\tau}, N^{\alpha}, N^{\alpha}-$ TMH) were clearly greater (unpolar solvent systems I-III) or smaller (polar solvent system IV) than those of the corresponding substrates. Solvent system IV can also be used with unpurified histamine containing enzyme preparations, since beyond the clear separation of $N^{a}-\mathrm{MH}, \quad N^{\tau}, N^{\mathrm{a}}$-DMH $, \quad N^{\mathrm{n}}, N^{\mathrm{a}}$-DMH and $N^{\tau}$. $N^{\alpha}, N^{\alpha}-\mathrm{TMH}$, also histamine and the reaction product $N^{\tau}$-MII could be separated from each other and from all other methylated histamines listed in Table 4. The $R_{f}$-values for $S$-adenosyl-1-methionine were given for comparison.

Thus with a very high probability the reaction products of $N^{*}$ - $\mathrm{MH}$ and $N^{*}, N^{*}$-DMH were $N^{\tau}, N^{* x_{-}}$ DMH and $N^{\tau}, N^{\alpha}, N^{*}$-TMH.

\section{DISCUSSION}

Detection of further methyl group accepting substrates of HMT. HMT was reported to be an enzyme with extremely high substrate specificity. This was shown for the enzymes from guinea-pig brain $[1,3]$. feline gut [3] and from livers of pigs [2, 22], as well as from animals of various phylogenetic stages of development [22], but never for HMT from any gastric mucosa preparation. Substances like histidine and structurally related imidazole amino acids, substrates of other methyltransferases, substituted imidazoles and other 2-aminoethyl substituted heterocycles were tested as potential methyl-group accepting substrates for HMT. but never substances being structurally (and thus in many cases pharmacologically) closely related to histamine itself.

Especially suitable in this respect was the investigation of methylated histamines which differ from histamine only by a small non-polar substituent as well as of 4-substituted imidazole compounds whose side chains had a more or less similar polarity as the 2-aminoethyl chain of histamine.

Actually it could be shown in this work that under incubation conditions which were optimum for the methylation of histamine beside this main substrate and $N^{\prime \alpha}$-MH [4] also $N^{\alpha} . N^{*}$-DMH, spinaceamine and I could be methyl-group accepting substrates.

Out of the substances tested in this work only $\mathrm{N}^{*}$ methylimidazole acetic acid (enzyme source: guinea pig brain [1]) as well as $N^{\tau}-\mathrm{MH}, N^{\prime \prime} . N^{\prime r}$-DMH and 4-hydroxymethylimidazole (enzyme source: pig liver [22]) (all in $0.1 \mathrm{mM}$ concentration) had been investigated before. In agreement with these reports we found no methylation of $N^{+}-\mathrm{MH}$ and $N^{r}$ methylimidazole acetic acid. Gustafsson and Forshell [22], however, observed a 9 per cent methylation of 4-hydroxymethylimidazole and even one of 31 per cent of $N^{x}, N^{x-}-D M H$, whereas no methylation of 4-hydroxymethylimidazole and only a small one of about 3 per cent of $N^{u x}, N^{k x}$-DMH was seen in this investigation. These discrepancies could be founded on differences in incubation conditions $(0.05 \mathrm{M}$ phosphate buffer ( $\mathrm{pH} 7.4$ ) (see Methods) vs 0.5 M Tris buffer ( $\mathrm{pH} 8.1)$ ), solvent extraction procedures for the reaction products [iso-amyl alcohol/toluene vs $n$-butanol (sec Methods)] and enzyme sources (pig fundus mucosa vs pig liver). Tris buffer in $0.5 \mathrm{M}$ concentration is a very strong inhibitor of IIMT(Barth et al. unpublished), whereas phosphate buffer does not influence HMT-activity. The reported butanol extraction procedure was inappropriate (cf. Results and Table 3) and the different enzyme source should not be the reason since HMT from various sources showed comparable $K_{m}$-values and was inhibited by various compounds to the same extent $[4,17]$. High blank values and a very small signal/blank-ratio (see Results) seem to be the most likely causes for the far too high methylation rate of $N^{\alpha}, N^{\alpha}$-DMH published by Gustafsson and Forshell [22]. Thus it seems very unlikely that $N^{a r}, N^{r-}$ DMH was methylated to a rate that was 33 per cent of that of histamine. Also from theoretical reflections such a high methylation rate (higher than that of $N^{r \text { - }}$ MH:) seems unlikely, since (1) the less pronounced electron-withdrawing effect of $N^{*}, N^{\alpha}$-DMH reduces the population of the imidazole- $N^{-}$-tautomer and (2) the bulky residue of two methyl groups at the side chain $N^{* x}$-nitrogen represents steric hindrance (see below).

Since $N^{\prime \prime}$-MH and $N^{* x} . N^{*}$-DMH could serve as methyl group acceptor substrates of HMT and since these substrates occur in nature $[8-1], 13,14,31-$ 35], it seemed interesting to identify the corresponding methylation products. By t.l.c. these products could be shown unambiguously to be $N^{+}, N^{t *}$-DMH and $N^{x}, N^{u}, N^{x}-$ TMH. This is the first report of at pathway by which $N^{* x}$-MH and $N^{* x} . N^{\alpha x}$-DMH could be metabolized. The products have not yet been isolated from any biological material. but the synthesis of $N^{\tau}, N^{\alpha}$-DMH and $N^{\tau} . N^{\alpha} . N^{\omega}$-TMH [25] performed especially for this work should make possible the microanalytical identification of these substances.

The theory of Code [36] that a gastric stimulant is in a "preferred position' as long as it is not metabolized within the gastric mucosa was invalid for histamine [23] and is now invalid for $N^{\prime x}-\mathrm{MH}$ and $N^{* x}, N^{* x_{-}}$ DMH, both substances postulated by the same author $[10,11]$ to be the final secretagogues. The fact, however. that the gastric secretagogues histamine, $N^{\mathrm{x}}-\mathrm{MH}$ and $N^{\mathrm{x}} . N^{\mathrm{v}}$-DMH are all metabolized to pharmacologically inactive products $[25]$ by the action of HMT emphasizes this enzyme's physiological importance in gastric secretion.

Structural characteristics of methyl group accepting substrates of HMT. Histamine is still the best substrate of HMT, but also methylated histamines, 1 and its methylated analogues, could serve as methylgroup acceptors. A methyl group is tolerated at the side-chain $N^{x}$-atom and to a smaller extent at the ring 5-position; it is accommodated less well at the ring 2-position. Substrates which were formally derived from histamine, methylated histamines or I by additional methylation were worse substrates than their parent compounds. This was valid both for a methylation of the $N^{\prime \prime}$-nitrogen atom of the 
side chain (histamine $>N^{\prime \prime}-\mathrm{MH}>N^{\prime \prime}, N^{\prime \prime}$-DMH: $5-$ $\left.\mathrm{MH}>5 . \mathrm{N}^{\mathrm{k}}-\mathrm{DMH}\right)$ and for the 5 position of the imidazole ring system (histamine $>5-\mathrm{MH}: \mathrm{N}^{*}$ $\mathrm{MH}>5 . N^{\prime \prime}$-DMH: I $>11$ ). An additional methylgroup in the side chain (in III), an ethyl-group (in 5-ethylhistamine) or any substitution in the 1-?- or 3-position of the ring system (in $N-2-N^{\prime \prime}$-MH or IV) vigorously reduced the methylation rate at the $N^{\tau}$-position of the imidazole nucleus. Like for $\mathrm{H}_{2}-$ agonists and $\mathrm{H}_{2}$-antagonists as well as for activators of HMT [17] also for presumed methyl-group itccep tor substrates the $\mathrm{N}-1, \mathrm{C}-2$ and $\mathrm{N}-3$ position of the imidazole nucleus must be unsubstituted.

Furthermore, bulky residues like in $N$-guanvihistamine and its homologue as well as in the $H_{2}$-recep. tor antagonists abolished any methylation of the imidazole nucleus.

Beside the necessity of an imidazole nucleus (dimaprit was no substrate for HMT, despite the fact that the isothiourea group simulates the functional nature of the imidazole ring of histamine [37]) the second important moiety was a basic centre within the side chain. since imidazole compounds with unpolar or negatively charged side chains could not serve as substrates. Also delocalization of the positive charge as in $N^{n}$-guanyl histamine abolistes substrate propertics.

Thus in the presence of S-adenosyl-1.-methionine HMT-catalysed methylation of unknown molecules must be considered. If these are imidazole compounds which have no $N^{\prime}-2$ - or $N^{n-}$ - but a 4 -substituent with a strongly basic side chain similar to that of histamine. Substitution in the ring 5-position seems only to play a role in steric access to the active centre.

Activation of histamine methylation by oher methyl-group accepting substrates. The previously described activation of HMT by $\mathrm{N}^{\prime \prime}-\mathrm{MH}[4]$ and $\mathrm{I}$ [19] have to be refocused since these substances were good substrates of HMT (Table 1 and 2) and the activation was determined by the amount of radioactivity extracted into the organic solvent mixture without analysing the radioactive products. Thus the increase of radioactivity was the sum of increased $N^{\top}$-MH formation and radionctive methylation product of the HMT-activating substance.

Thus the reported 22 per cent activation of IIMT by $0.1 \mathrm{mM} \mathrm{N} N^{\prime \prime}-\mathrm{MH}|4|$ | consists of 12 per cent methylation of $N^{\prime \prime}$-MH (Table 1) and only the difference of 10 per cent can be ascribed to in activation of HMT.

I ( I mM) seemed to "activate" HMT by 17 percent [19]. Actually this increase in extracted radioactivity can fully be ascribed to the methylation of this compound (Table 2), whereas in $0.1 \mathrm{mM}$ and $10 \mu \mathrm{M}$ concentration only 41 per cent resp. 33 per cent of the observed activation of 27 per cent resp. 9 per cent were caused by this direct methylation of the activator.

Al! other substances which were good activators of HMT $[4,17-20]$ could not serve as methyl-group acceptors to any relevant extent. Thus. $\mathrm{C}$.g. the clinically important histamine- $\mathrm{H}_{2}$-recteptor antagenists metiamide and cimetidine exert their action on histamine catabolism only by a strong activation of HMT $\mid 17,19]$. On the other hand there did not exist any methyl-group accepting substrate of HMT up till now, which did not activate HMT-catalysed methylation of histamine. what indicates a great similarity of the active and the postulated allosterie centre $[18]$ of HMT

Significance of a redeced methy-group acesptor substrate specificity of HMT for the rediometric and the fluorometric histamine determination. HMT is an enzyme with a high, but not absolute acceptor substrate specificity for histamine. Becaluse of this property, the methylation reaction of histamine is used for its radiometrir determination in tissues and body fluids (for a survey see ref. (b) and for testing the specificity of the fluorometric histamine ansay $|7|$. Since $N^{\prime \prime}-\mathrm{MH}, N^{n}, N^{\prime \prime}-\mathrm{DMH}$, and spinaceamme arte further substrates of HMT and occur in nature $\mid 8-$ $11,13,14,31-3.51$, the determination of histamine by the isotope test ean only he called specitic, if the absence of these interfering substances was shown. The fluorometrie determination of histamine does. however. not ratise this difficulty, since only the testing of specificity is concerned. whereas $N^{\prime}-\mathrm{MH}$. $N^{\prime \prime}, N^{\prime \prime}$-DMH and spinaceamine de nor form fluorescing complexes with ophthaldialdehyde $|7|$. Therefore any interference with the test system can better be avoided by using the fluorometric method. whereas for the application of the radiometric assaty caution seems necessary.

Acknowledgemen-Supported by grant los 190.7 of Deutsche Forschungsgemeinschift.

\section{RFFHKENCKS}

1. D. D. Brown. R. Tombhich and 1. Axelrul. I. hint. Chem. 234. 2948 (1959).

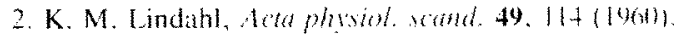

3. A. Thithapandahat Bioghom hiophes. Res. Cimmon. 47. $301(1972)$.

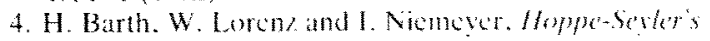
Z. physiol chom. 354. 1021 (1073).

5. S. H. Snyder. R. J. Batdestami and I Axelrod, I. Phamace exp. Ther. 153, 5tt (196(n).

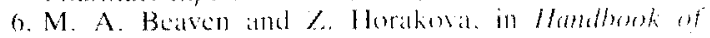
Experimemal Phamacolesy (E.t. M. Rerchat e Silvit. Vol. 182. p. 151 Spmoser Berlm (1075)

7. W. Lorenz. H. Barth. M. Thermimn. A. Schmal. Is


Chem. 355. $1999(1974)$.

8. H. Navert, E. V. Flock. (i, M. Tree and C. F. Code. Physiologist $12,313(19)(19)$.

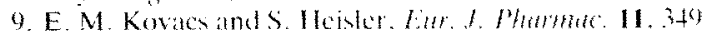
(19)70).

10. C. F. Code, W. E, R. Ciren. II D. Rithie, I. I. Schlegel and I. C. Kennedey. (im 13, s43 11972).

11. C. F. Code, W. E. R. Green, I C. Kenneder, H. D). Ritchic and J. F. Schleget. Am. I. Phisiol 230. 214 (1976).

12. S. Masinski, B. Schuputt. K. A. Kewar and K. Sening. Digestion 15. 497 (1977).


Arm. 25, 394 (1957).

14. H. Navert. J. Chromat. 106. $218(1975)$.

15. H. Barth. Thesis Unisersity of Munch (1974).

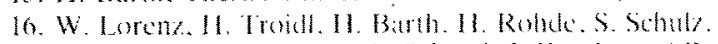
H. Becker. P. Dormann. A. Sohmal. I. Kusche and R.

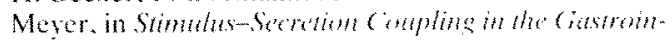
testinal Trat (lik. R. M. (asc and II. circhell). p. 177. MTP Pross. Lancister (19)6). 
17. H. Barth. 1. Niemeyer and W. Lorenz. Agents Actions 3, $138(1973)$.

18. H. Barth, I. Niemeyer and W Lorenz, in Imernational Symposium on Histamine $\mathrm{H}_{2}$-Receptor Anagonists (Eds. C. I. Wood and M. A. Simkins), p. 115. Deltakos, London (1973).

19. H. Barth and W. Lorenz. Agents Actions 8. $359(1978)$.

20. H. Barth. I. Niemeger and W. Lorenz. Agents Artions 4. $186(1974)$.

21. W. Lorenz. H. Barth, H. E. Karges, A. Schmal, P. Dormann and I. Niemeyer, Agents Actions 4. 324 $(197 .+)$

22. A. Gustafsson and (j. P. Forshell, Acta chem seand. 18. $2069(1964)$

23. W. Lorenz. H. Barth and E. Werk. Natmin-Schmiedeberg's Arch. Phammak. 267. 421 (1970).

24. O. H. Lowry. N. I. Rosebrough, A. L. Farr and R. J. Randall. J. biol. Chem. 193. 265 (195)).

25. W. Schunack. Arch. Fham (Weinh.) 311. 552 (1978).

26. K. Wegner, E. Fritschi and W. Schunack, Arch. Pharm. (Weinh.) 311, 98 (1978)
27. W. Schunack, H. Engler and E. Fritschi, Arzneimithel Forsch. 29, 595 (1979).

28. S. Ii. Snyder and J. Axelrod, Biochim. biophys. Acta 111. $416(1965)$

29. M. E. Parsons, D. A. A. Owen. C. R. Ganellin and G. J. Durant. Agents Actions 7.31 (1977).

30. N. R. Peden, J. H. B. Saunders and J. H. B. Wormsley, Lance i, 690 (1979).

31. V. Erspamer. T. Vitali, M. Roseghini and J. M. Cei. Experientia 19. 346 (1963).

32. V. Erspamer, T. Vitali, M. Roseghine and J. M. Cei, Archs Biochem. Biophys. 105, 620 (1964).

33. V. Erspamer, M. Roseghini and J. M. Cei. Biochem. Pharmac, 13. 1083 (1964).

34. V. F. German. J. Pharm. Sci. 60, 495 (1971)

35. M. Roseghini, R. Endean and A. Temperilli. Z. Naturforsch 31c. $118(1976)$.

36. C. F. Code in Ciba Foundation Symposim on Histamine (Eds. G. E. W. Wolstenholme and C. M. OConnor), p. 184. Churchill, London (1956).

37. G. J. Durant. C. R. Ganellin and M. E. Parsons, Agents Actions 7, 39 (1977) 